slums, near slums or in overcrowded conditions, Britain may already be overpopulated. Certainly it will not be possible to reconcile the present trend with the traditional fondness for dispersed living in Britain.

The two Acts that have now been passed show little sign either of meeting the ideal of preventing unwanted children or of making substantial inroads on the rate of population growth. Despite the apparently liberal trends and the so-called permissiveness of society, the old prejudices are still active. The British Medical Association has set its face against the social clause of the Abortion Act. More seriously, by July of this year, a year after the Family Planning Act came into force, less than one sixth of local health authorities had provided the full family planning service empowered by the Act. Two-thirds of the authorities had set up a restricted service while another sixth had taken no action (Family Planning, October 1968, supplement).

Why are the local health authorities dragging their feet? Why are they being allowed to do so ? The Family Planning Act is merely permissive. Compulsory powers, it is argued, would be incompatible with the democratic process. But no individual is being forced to use family planning services; local authorities have merely been asked to make them available. And such arguments are not presented when the Ministry of Health decides, for example, to vaccinate the child population against measles.

Local health authorities apart, there are other grounds for dissatisfaction at the role of individual doctors in giving contraceptive advice. For one thing, not all of them are as well informed of modern practice as could be wished. For another, there have been instances of the sort where a university health service doctor has recommended contraceptives for a patient and informed the patient's family doctor, who has then disagreed with the decision.

There are a number of cogent reasons why government action should ensue to attenuate the widespread prejudice now thwarting the intention of its recent Acts. There is also a job for the medical association to do. As for religious organizations, the Church of England has long arrived at a liberal attitude towards contraception, while whatever the Roman Catholic hierarchy may say, a survey by Professor D. V. Glass has claimed that about 80 per cent of Catholic women in England have used contraceptive methods-other than the so-called safe period-at one time or another. Another question to which attention should be given is the support of demography. In Britain, the only government funds for demography are a handful of studentships awarded by the SSRC; demographic research at the London School of Economics, for example, is supported in the main by the Ford Foundation. Demographic predictions in the past have been highly inexact; no one expects that they could be made absolutely precise, but more research funds would at least open the way to a significant improvement in accuracy. It is, after all, important to know if the population is likely to increase beyond control and, if so, what steps should be taken and when.

\section{NUCLEAR POWER Cheaper Fuel by Centrifuge}

GREat Britain, West Germany and the Netherlands have agreed to explore the possibility of collaborating in the development of the gas centrifuge method for enriching uranium. This important announcement was made after a meeting which took place in the Hague on November 25. The terse communiqué which was issued conveys little, but there will be plenty of political and economic speculation to fill the gaps left by the six ministers who were present.

For one thing, the agreement to exchange information (subject to Government approval) clearly implies a recognition that the centrifuge has become a serious rival to the traditional method of enrichment, gas diffusion. Reports, principally from the Netherlands, had begun to make this seem likely some months ago, and the meeting will be taken as a confirmation that the breakthrough is a real one. The plan is to get the approval of the three governments before holding another meeting, which will take place in London early in the New Year. If, as seems likely, it is then clear that collaboration would be worthwhile, it can be put on a proper footing. After that, it may be possible to proceed immediately to the building of a plant. To start with, it could be relatively small-the beauty of the method is that it is possible to add extra capacity as the demand increases. With the gas diffusion method, the very heavy capital investment must all be made right at the start.

The centrifuge method offers two principal advantages. The initial capital investment is very much smaller, and the electricity consumption of the plant, when running, is only one-seventh of the consumption of a diffusion plant of similar size. Quite clearly, there is now a general recognition that centrifuge plants are mechanically feasible and that they would produce enriched uranium at a cheaper cost. For the United Kingdom, this is an important point, because British reactors are designed for use with enriched fuel. The greater the number of sources of supply, and the cheaper the enriched fuel is, the more likely foreign buyers are to look favourably at British designs. Cooperation also looks a good bet for Britain-although Mr Wedgwood Benn's answer in the House of Commons on November 22 says that the UKAEA has been pursuing centrifuge development for some years, there is not much doubt that Britain has more to learn from the Dutch, particularly, than they have to learn from Britain. An indication of the seriousness with which the Ministry of Technology regards the new developments is given by the information that it has delayed the decision which would have sanctioned the second stage of the development of the Capenhurst gas diffusion plant. The first stage of the reactivation of Capenhurst, decided on in 1965, is complete, and the second stage is about to begin. Until information about the centrifuge is available, the ministry has delayed the decision.

The decision to collaborate, of course, raises political issues of some delicacy. The centrifuge method of enrichment, because it offers a much greater chance of concealment than gas diffusion, would appeal to any country hoping to make nuclear bombs on the quiet. For this reason, the communiqué states that any collaborative agreement reached will have to be 
consistent with the three governments' policies to the non-proliferation treaty. In the sense that Britain is offering to West Germany information which might make it easier for her to build nuclear weapons, the agreement is controversial. But, of course, it would be better that this information formed part of a tripartite agreement than if West Germany were to proceed alone. Besides, if West Germany's civil nuclear plans go as is hoped, it will become a substantial plutonium producer in the next ten years or so, offering an alternative route to nuclear weapons.

\section{MEDICAL EXAMINATIONS \\ New Ways of Finding Dociors}

Many have criticized the system of examinations for medical students, but few-particularly among the students themselves-have set out practicable alternatives. A step in this direction has now been taken, in a World Health Organization publication by J. Charvat, professor of medicine at the University of Prague, Christine McGuire, of the College of Medicine, Chicago, and Victor Parsons, senior lecturer in medicine at King's College Hospital Medical School, London (Public Health Papers, 36; A Review of the Nature and Uses of Examinations in Medical Education).

Any technique for measuring competence should fulfil three criteria. It should yield objective datathat is, independent observations of different experts should agree. It should be valid in the sense that it should measure what it claims to measure. Third, examinations should be reliable, yiclding consistent scores when given repeatedly to the same group under the same conditions. They should be designed to measure not only knowledge but also skill in solving problems, the ability to communicate with patients, colleagues and other members of health teams as well as the capacity for original work. Under the present system, the report suggests, examinations tend to sample only a narrow range of the requisite knowledge and skills. The questions are sometimes trivial, and the student may be forced to answer in terms of the provincialism or personal views of the examiner.

One new development is the "process approach" to determining whether an examination measures simple recall of isolated information or, at the other extreme, the ability to solve complex problems. Most of the studies in which this approach has been used show that 75-95 per cent of questions currently in use in the United States and Canada measure only recall of information. A number of new tests have been designed to measurc the achievements of the student in the cognitive and psychomotor domains. These range from multiple-choice tests and questionnaires to objectively rated diagnostic or therapeutic interviews with an assigned patient. New approaches to the design of essay and oral examinations can be used to measure the student's ability to communicate with a colleague or a patient or to assess his ability in taking a patient's history and his judgment in determining and defending a plan of management for a specific patient. Two new methods are being introduced as a means of objectively assessing a student's professional habits, attitudes and values. Objective anecdotal statements of a student's professional behaviour, by an instructor accumulated during medical school, are used to identify his chief qualities. The second approach is to set out to identify certain variables in professional behaviour such as response to criticism.

\section{GERMAN SATELLITES \\ Up with the Mark}

\author{
from our Special Correspondent \\ Munich, November 26
}

THE reconstruction of Germany's aerospace industry has involved several famous names of German aviation -admittedly now only shadows of their former selvesin an ambitious space programme. For some years now, the Bölkow group of companies has strenuously searched for a merger within the German aircraft industry with the intention, it seems, of forming an aerospace industry on a European scale. In this it has been encouraged by the German Government, which has wanted to see a merger of the aerospace industry in south Germany. Last month, Bölkow managed to acquire the Messerschmitt company, and the new Messerschmitt-Bölkow group located at Munich is involved with the HEOS-A satellite which, with luck, should become ESRO's third successful satellite early in December, with a third stage of Europa I, with the first German research satellite and with a proposed solar probe in coopcration with the Americans.

Another historical name, Junkers, also has a part in the merger, having been acquired by Messerschmitts in 1965. Junkers is primarily contractor for HEOSA, responsible for the satellite's basic structure and the integration of its experiments.

The novelty of HEOS is its highly eccentric orbit taking it to a distance of between 200,000 and 300,000 kilometres from the Earth at apogee. This orbit was chosen so that HEOS would traverse the largely unknown boundary of the magnetosphere, the nearEarth region dominated by the terrestrial magnetic field. A measure of the eccentricity of the orbitwhich HEOS takes five days to complete-is that the satellite is influenced by the masses of the Sun and the Moon. The scheduled launch date for HEOS is December 5, when it will be fired from Cape Kennedy by a Thor-Delta vehicle. If the launch is successful, HEOS will then become ESRO's third satellite launched this year, and the value of the experiments it is carrying into a comparatively unexplored region of space should go a long way to appcasing scientists' doubts about the organization.

Looking further ahead, the Messerschmitt-Bölkow group will be responsible next year for launching the first German research satellite Azur-a 78 kilogram vehicle for inner radiation belt measurements. A more important project is an interplanetary solar observation satellite. So far it is still in the design stage; the specification calls for a probe to explore the solar plasma and interplanetary matter up to a perihelion of 0.3 astronomical units, by German and NASA experimenters. The talk is of a launch date in 1973-74.

\section{PLANNING}

\section{How to keep Everybody Happy}

At last planners are realizing that countryside planning is as vital as urban planning. In a country as small as 